DOI: http://doi.org/10.21698/simi.2018.ab25

\title{
INDUSTRIE 4.0 AND THE TRIPLE BOTTOM LINE OF SUSTAINABLE DEVELOPMENT
}

Cristian Theodorescu $^{1}$, Carol Blaziu Lehr ${ }^{2}$, Alina Mirela Constantin ${ }^{2}$

${ }^{1}$ International Development Norway-021621-Bucharest, Romania, christit@gmail.com

${ }^{2}$ National Research and Development Institute for Industrial Ecology - ECOIND, 71-73

Drumul Podu Dambovitei, district 6, 060652, Bucharest, carol.lehr@incdecoind.ro, alina.constantin@incdecoind.ro, Romania

Keywords: cyber world, environmental \& social impact, Industrie 4.0, internet of things, sustainable development

\section{Introduction}

The term "Industrie 4.0" was coined at the turn of the new millennium in Germany and became a designation for what is believed to be the $4^{\text {th }}$ Industrial Revolution (IR). These IR include:

- $\quad 1^{\text {st }}$ IR: steam power, mechanization (XVIII-th Century)

- $\quad 2^{\text {nd }}$ IR: electricity, mass production (end of XIX-th Century, beginning of XX-th Century)

- $\quad 3^{\text {rd }}$ IR: computers, INTERNET and large scale automation (second half of the XX-th Century)

- $\quad 4^{\text {th }}$ IR: Internet of Things (IoT), Cyber World, Cloud computing, etc.

As a Strategic Initiative of the German economy, "Industrie 4.0" has progressed in the last 7 years as a well structured approach aiming to take advantage as soon as possible of all the advantages and opportunities present in the whole bunch of new perspectives opened by the IT\&C domain (computers and INTERNET for everyone, high-speed hardware, large data storage facilities offered by cloud computing, advanced software that can manage enormous volumes of data via DataMining and BigData paradigms. The vision of "Industrie 4.0" is a high performance, flexible smart industry totally controlled by computers on the base of four fundamental principles:

- Interoperability: equipment and humans communicate with each other via the Internet of Things (IoT)

- Information: sensor data add continuously information enabling upgrading of computer models of the real world.

- Technical support for carrying out difficult tasks and solving emergencies by minimizing risks.

- Real time, swift, decentralized decisions: companies become autonomous relegating to humans only conflicting situations or exceptions.

\section{Materials and methods}

Stressing upon smart performance, high technical and economic efficiency leaves apart the environment and the social impact in the"Industrie 4.0" strategy. The paper tries to put the environment + social at their place by taking the following steps:

a. "Industrie 4.0" must go well beyond smart enterprises, high profit, less human work. The Environment and the Social Impact must be included in 
all models of specific industrial processes that take advantage of IoT. Environmental aspects became global long before the industrial facilities could communicate and act in integrated, concerted manner

b. "Industrie 4.0 " is a transdisciplinary process (technical, enviro, economics, IT specialists, communities). It must be expected that the secrets of IoT, DataMining, decision making become familiar to all kind of specialists involved in "Industrie 4.0" implementation.

c. Those called to carry out the Industrie 4.0 revolution are the same people that implemented the Cleaner Production paradigm and the triple bottom line approach to sustainability. Industrie 4.0 calls for a vast expansion of their responsibilities so they must learn computer programming and not leave this task to IT specialists. Computer programs must have no secrets to specialists for Industrie 4.0. All participants must understand, modify, upgrade such programs on very short notice and with minimal expenses and with minimal help from IT experts.

d. It is the essential responsibility of all working in implementing "Industrie 4.0" to ensure the integrity and protection of data. This will be particularly difficult since public reporting environmental aspects in more detail could give hints to other companies about internal processes in a given company, overcoming confidentiality barriers.

e. Decision processes must become the task of industry + environmental specialists + communities. Networking together companies, R\&D entities, Administration, Law Enforcing Institutions, NGOs and communities must be driven by efficient and effective policies, aligned, in the Romania case, to all EU initiatives. Romanian specialists should take part to the construction of the new legal framework right from the beginning.

\section{Results and conclusions}

"Industrie 4.0" should become a strategic tool to transform the society basic cultural values, trending toward integration, cooperation, mutual understanding, environmental and social awareness. Limiting"Industrie 4.0" to company levels, technical IoT, economical efficiency would be a gross error. An expanded"Industrie 4.0 " to include the environment and the social is the only way the initiative becomes successful and essential to future human development. 